Article

\title{
Dust Emission Thresholds in Loess Soil Under Different Saltation Fluxes
}

\author{
Aviv Rubinstein ${ }^{1}$, Meni Ben-Hur ${ }^{2}$ id and Itzhak Katra ${ }^{1, *}$ \\ 1 Department of Geography and Environmental Development, Ben Gurion University, \\ Beersheba 8410501, Israel; avivru@post.bgu.ac.il \\ 2 Institute of Soil, Water \& Environmental Sciences, Agricultural Research Organization-The Volcani Center, \\ Rishon LeZion 7505101, Israel; meni@volcani.agri.gov.il \\ * Correspondence: katra@bgu.ac.il
}

Received: 7 August 2020; Accepted: 26 August 2020; Published: 27 August 2020

check for updates

\begin{abstract}
Soil-derived dust particles produced by aeolian (wind) processes have significant impacts on humans and the Earth's systems. The soil particle size distribution is a major soil characteristic in dust emission models. Yet empirical information on the dependence of dust emission thresholds on soil particle size distribution is still lacking. The main goal of this study was to explore the dust emission threshold from semi-arid loess soil samples by a targeted wind-tunnel experiment. The results clearly show that the dust emission threshold is associated with the saltation threshold with no distinct direct aerodynamic lifting of the loose dust particle. The dust flux depends on the amount of the clay-silt fraction in the soil, the shear velocity, and the saltation flux under certain shear velocity. The study aimed to advance our understating of the dust emission processes, and to provide empirical information for parametrization in dust emission models and for management strategy of soils in preventing dust emission.
\end{abstract}

Keywords: wind tunnel; particulate matter; soil erosion; particle size distribution

\section{Introduction}

The majority of aerosol mass in the atmosphere is related to soil-derived dust particles produced by aeolian (wind) processes [1]. Annual global dust emissions from soils into the atmosphere are estimated to be as high as 3000 million tons, including particulate matter (PM) that is less than 10 micrometers in diameter (PM10). The emission of PM10 from soils is directly associated with loss of soil nutrients (clays and organic matter) [2], air pollution, and substantial health risks [3,4]. Other environmental impacts of atmospheric dust refer to the Earth's global energy balance and climate sensitivity through radiative effects and climate feedbacks [1]. Considering these various important impacts of soil dust on the Earth system, it is critical to estimate accurately the dust emission. Although models that estimate the dust emission from soils have been improved [5,6], still there is large disagreement between the empirical results and their estimated values by the models [1]. These discrepancies are partly a result of our gap in understanding the threshold wind friction velocity needed to mobilize soil particles.

Dust emission depends on the soil properties and on the wind shear stress exerted on the soil surface. The shear stress is characterized by the friction velocity $\left(\mathrm{u}_{*}\right)$, which express the velocity gradient in boundary layer flow. The threshold friction velocity $\left(u_{* t}\right)$ is then the minimum value of the shear velocity $\left(u_{*}\right)$ for which the soil experiences dust emission [7,8]. This threshold friction velocity has been the subject of many experimental studies, starting with the pioneering work of Bagnold [9]. His work revealed that, for a bed of monodisperse (single particle size) beds, the threshold friction velocity has a minimum around $100 \mu \mathrm{m}$. Larger particles are more difficult to mobilize because of the increased gravitational force, and smaller particles are more difficult to mobilize because of the 
increased cohesive forces [10]. The cohesive forces of the clay and fine silt particles limit the dust emission form soil by direct aerodynamic lifting of loose particle [8]. Consequently, dust is normally emitted by the impacts of more easily mobilized sand-sized particles. These "saltators" undergo ballistic trajectories that impact the soil surface. The resulted saltation process enables the entrainment of cohesive dust particles by the disintegration of the soil aggregates $[7,8,11]$. However, the threshold of motion of monodisperse beds of sand particles is unrealistic because dust-emitting soils contain a wide range of particle sizes $(<1 \mu \mathrm{m}$ to $\sim 1000 \mu \mathrm{m})$.

Many soils throughout the world are subjected to increase human activities, and dust emission, in particular, in semi-arid climates [12]. The soil disturbance resulted in disintegration of the soil aggregates, which produce small aggregates and loose sand particles that are available for saltation [11]. It is generally assumed that soils with a higher amount of large aggregates have stronger resistance against erosive forces [13]. Yet, the effect of the soil particle size distribution on the saltation and dust emission threshold is poorly understood, and hence poorly parameterized in dust emission models. Consequently, predictions of future environmental changes and the resulting changes in soil properties and wind erosion are limited by this missing information of how dust emission threshold are affected by the particle size distribution.

The main goal of this study was to examine the dependence of dust emission threshold on soils with different distribution of dust and sand-sized particles. To this end, we analyzed soil samples that are characteristics of a semi-arid loess soil and conducted a targeted experiment on dust emission with a boundary-layer wind tunnel to provide empirical information on the link between soil particle size distribution and saltation and dust emission thresholds.

\section{Materials and Methods}

\subsection{Soil Sample Setup}

Two different materials, loess soil and dune sand, were used to form the experimental soil samples with specific dust $(<63 \mu \mathrm{m}$ ) and sand contents (see Section 2.2). Those materials were collected from two sites in the northwestern Negev, Israel, where sand transport and dust emission have been extensively studied. The loess material (Figure 1a) was sampled from the topsoil $(0-\sim 2 \mathrm{~cm})$ of a natural area with no human disturbance [11]. The soil contained a mix of clay, silt, and sand particles, which is an ideal case for dust emission by saltation. The sand material was collected from an active sand dune in the northwestern Negev. The Negev dunefield is located in the eastern part of the Sinai- Negev erg [14]. The sand has a typical size (mode at $\sim 250 \mu \mathrm{m}$ ), and it contains less than $2 \%$ of clay- and silt-sized particles [15]. The bulk materials of the loess and sand samples were analyzed to determine the particle size distribution (PSD) by the ANALYSETTE 22 MicroTec Plus (Fritsch, Idar-Oberstein, Germany) laser diffraction, which measures particles in the size range of $0.08-2000 \mu \mathrm{m}$. The replicates $(100 \mathrm{mg})$ of each sample were dispersed in Na-hexametaphosphate solution $(0.5 \%)$ by sonication ( $38 \mathrm{kHz})$. PSD data was calculated using the Fraunhofer diffraction model with a size resolution of $1 \mu \mathrm{m}$ using MasControl software (Version 1.8, Idar-Oberstein, Germany) (Figure 1b).

The loess material was first crushed for aggregate disintegration, and then was sieved by an electronic sieving apparatus with horizontal and vertical motions (RETSCH AS 300 Control, Haan city, Germany) to receive the dust material $(<63 \mu \mathrm{m})$. The sieved material was analyzed by the laser diffractometer to ensure that the particle size is less than $63 \mu \mathrm{m}$. The sand dune was added to the loess-sieved material $(<63 \mu \mathrm{m})$ in a known weighted ratio to form samples with specific weight percentage of silt-clay and sand fractions. The samples were kept at air-dry state $(<1.5 \%$ gravimetric water content) to eliminate effect of soil-water mass [16]. Four reference samples of $15 \mathrm{~kg}$ each with various sand/dust percentage were prepared: "sand 100\%" (0\% dust); "sand 90\%" (10\% dust); "sand 75\%" (25\% dust); "sand 50\%" (50\% dust). The samples were analyzed by the laser diffractometer to test the sand and dust fractions (Figure 1b). 

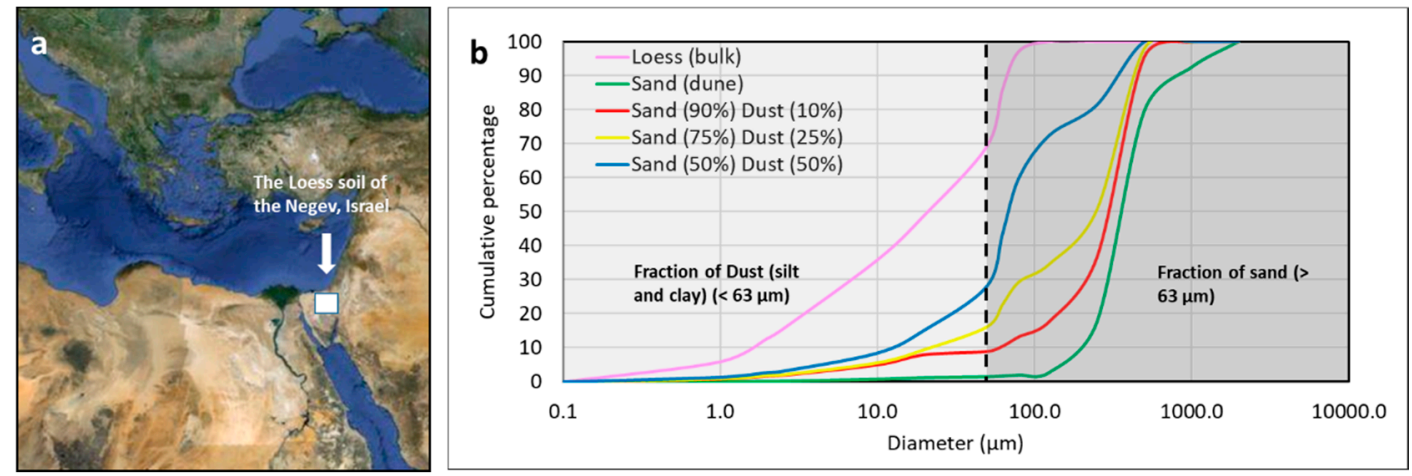

Figure 1. (a) Location of the loess soil in the Negev (Israel), Eastern Mediterranean. (b) Particle size distribution of the soil samples used for the experiments: sand dune and various mixes of sand and dust fractions that were used for the wind tunnel experiment. The dust fraction, which used for the preparation the mixed samples, was extracted from a loess (bulk) soil.

\subsection{Wind Tunnel Experiment}

The experiment on dust emission threshold was conducted with a boundary layer wind tunnel [16-18]. The wind tunnels enable aeolian simulations under standardized quasi-natural wind conditions and provide quantitative information on aeolian particle transport in the field and dust emission rates from soils [19-22]. The wind tunnel has a cross sectional area $0.5 \times 0.5 \mathrm{~m}$ with open-floored working sections of up to $10 \mathrm{~m}$ length. The tunnel fan was operated at nine fan frequencies $(8,11,14,17,23,26,29,32,35$, and $38 \mathrm{~Hz})$ to represent a wide range of wind velocities.

The wind velocity profile was measured for each fan frequency at different heights above the tunnel bed: $0.02,0.035,0.05,0.075,0.10,0.15,0.20,0.25,0.30,0.35,0.40$, and $0.45 \mathrm{~m}$. The wind measurement was conducted with a micro-vane anemometer with vane diameter of $14 \mathrm{~mm}$ that measure wind velocities at the range of $\sim 0-30 \mathrm{~m} \mathrm{~s}^{-1}$ with reading resolution of $0.1 \mathrm{~m} \mathrm{~s}^{-1}$ (KIMO vt 200, Ontario, Canada). The data are logged at time interval of $5 \mathrm{~s}$ for each test. The data were analyzed to determine the height of the boundary layer, the average wind velocity in the boundary layer, and the wind shear velocity $\left(\mathrm{u}_{*}\right)$. The wind shear velocity is expressed by the Prandtl-von Karman equation [8]:

$$
\frac{\mathrm{u}}{\mathrm{u}_{*}}=\frac{1}{\mathrm{~K}} \ln \left(\frac{\mathrm{z}}{\mathrm{z}_{0}}\right)
$$

where $u$ is the wind velocity $\left(\mathrm{m} \mathrm{s}^{-1}\right)$ at height $\mathrm{z}(\mathrm{m}), \mathrm{z}_{0}$ is the aerodynamic roughness length of the surface $(\mathrm{m}), \mathrm{u}_{*}$ is the shear velocity $\left(\mathrm{m} \mathrm{s}^{-1}\right)$, and $\mathrm{K}$ is von Karman's constant $(\approx 0.4)$.

Each soil sample was tested under all the fan frequencies/wind velocities. Overall 108 tests were conducted in this study (4 soil samples, 9 wind velocities, 3 replicas). Each run was last $30 \mathrm{~s}$ to record the trend of sand transport and dust emission. A series of traps were placed in the tunnel along the wind direction. The transported particles were collected at height of $0-0.10 \mathrm{~m}$ above the tunnel bed. After the experiment, the sediments in the traps were analyzed for the relative contents of sand and dust $(<63 \mu \mathrm{m})$ fractions. In addition, the mass of the transported particles calculated as saltation flux $\left(\mathrm{Q}, \mathrm{kg} \mathrm{m}^{-1} \mathrm{~s}^{-1}\right)$ that cross a width of $1 \mathrm{~m}$ [15].

Dust concentrations $\left(\mu \mathrm{g} \mathrm{m}^{-3}\right)$ PM10 were recorded by a light-scattering device, DustTrak DRX 8534 (TSI, Shoreview, MN, USA), in the range of $0.001-150 \mu \mathrm{g} \mathrm{m}^{-3}( \pm 0.1 \%$ of reading) at sec- 1 intervals, was placed at $15 \mathrm{~cm}$ above the tunnel bed. The recorded PM10 concentrations were converted into mass flux (Fpm) emitted from the soil surface $\left(\mathrm{kg} \mathrm{m}^{-2} \mathrm{~s}^{-1}\right)$ based on the wind tunnel dimensions and the area of the sand bed [15]:

$$
\mathrm{F}_{\mathrm{PM}}=\left(\mathrm{C}_{\mathrm{PM}}-\mathrm{C}_{\mathrm{bg}}\right) \times \mathrm{V}_{\mathrm{air}} \times \mathrm{A}_{\mathrm{cs}} / \mathrm{A}_{\mathrm{P}}
$$


where $C_{P M}$ is the recorded PM concentrations $\left(\mathrm{kg} \mathrm{m}^{-3}\right)$ from the soil, $C_{\mathrm{bg}}$ is the average PM background concentration $\left(\mathrm{kg} \mathrm{m}^{-3}\right), \mathrm{V}_{\text {air }}$ is the mean horizontal wind velocity in $\mathrm{m} \mathrm{s}^{-1}$ (average over height), $\mathrm{A}_{\mathrm{cs}}$ is the cross-section (height $\times$ width) of the wind tunnel $\left(\mathrm{m}^{2}\right)$, and $A_{p}$ is the area $\left(\mathrm{m}^{2}\right)$ of the experimental plot (length $\times$ width).

The recorded PM10 flux $\left(\mathrm{kg} \mathrm{m}^{-2} \mathrm{~s}^{-1}\right)$ and sand fluxes $\left(\mathrm{kg} \mathrm{m}^{-1} \mathrm{~s}^{-1}\right)$ were used to calculate the sandblasting efficiency a $\left(\mathrm{m}^{-1}\right)$, which is the vertical dust flux produced by a unit horizontal sand saltation flux, and is an important property to inform the dust emission by saltation process [23]:

$$
\mathrm{a}=\mathrm{F}_{\mathrm{PM}} / \mathrm{Q}
$$

where $\mathrm{F}_{\mathrm{PM}}$ is the average PM10 vertical mass flux $\left(\mathrm{kg} \mathrm{m}^{-2} \mathrm{~s}^{-1}\right)$, and $\mathrm{Q}\left(\mathrm{kg} \mathrm{m}^{-1} \mathrm{~s}^{-1}\right)$ is the averaged horizontal sand flux integrated over the hole experiment time for all sand grain sizes.

\section{Results}

\subsection{Wind Profile}

The profiles of the wind measured in the wind tunnel under all fan frequencies are characterized by a logarithmic increase in wind velocity of each fan frequency as an increase in height (Figure 2a). The wind shear velocity $\left(u_{*}\right)$ for each wind profile was calculated by the von Karman's equation (Section 2.2). The shear velocities are at the range of 0.17 to $0.56 \mathrm{~m} \mathrm{~s}^{-1}$ (Figure 3). This include shear velocities that are below the saltation threshold $\left(<0.28 \mathrm{~m} \mathrm{~s}^{-1}\right)$ in laboratory and field experiments $[15,23]$. Then, the wind shear velocity was predicted by the fan frequency $\left(R^{2}=0.98\right)$ (Figure $2 b$ ).
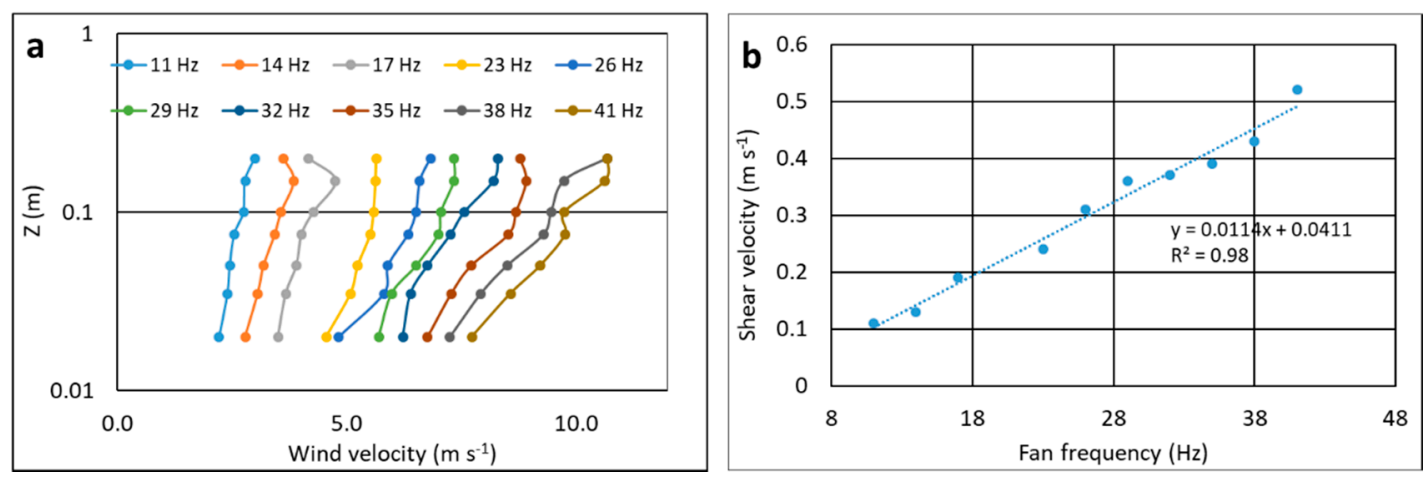

Figure 2. (a) Wind velocity $\left(\mathrm{m} \mathrm{s}^{-1}\right)$ measured at different heights above the tunnel bed ( $\mathrm{z}$ ) under different fan frequencies $(\mathrm{Hz})(\mathbf{b})$ Correlation between the fan frequencies applied in the wind tunnel and the calculated shear velocity $\left(\mathrm{u}_{*}\right)$.

\subsection{PM10 Concentration}

The PM10 concentrations resulted from dust emission are presented in Figure 3. With the sand dune sample, no dust concentration, which is above the background value $\left(30 \mu \mathrm{g} \mathrm{m}^{-3}\right)$, was recorded in all wind velocities. The background value was determined as the maximum atmospheric PM10 concentration in the wind tunnel before the experiment. With all the soil samples, there is a trend of increase in the dust concentrations as the shear velocity increases. The dust emission in the "sand 90\%" sample resulted in a range of PM10 concentrations from $30 \mu \mathrm{g} \mathrm{m}^{-3}$ (background value) to a maximum value of $12,856 \mu \mathrm{g} \mathrm{m}^{-3}$ under the shear velocity of $0.52 \mathrm{~m} \mathrm{~s}^{-1}$. At low wind shear velocities $\left(<0.24 \mathrm{~m} \mathrm{~s}^{-1}\right)$, no distinct PM10 concentration was recorded. In the sample "sand $75 \%$ ", only a very low PM10 concentration $\left(44 \mu \mathrm{g} \mathrm{m}^{-3}\right)$ was recorded at $0.19 \mathrm{~m} \mathrm{~s}^{-1}$. As in the $90 \%$ sand sample, the significant increase in concentration was obtained in the transition from 0.31 to $0.39 \mathrm{~m} \mathrm{~s}^{-1}$, in which the mean PM concentration was raised from 944 to $6429 \mu \mathrm{g} \mathrm{m}^{-3}$, which is higher than at $90 \%$ sample. The highest mean concentration $\left(14,309 \mu \mathrm{g} \mathrm{m}^{-3}\right)$ was recorded at $0.52 \mathrm{~m} \mathrm{~s}^{-1}$, almost two times higher compared 
with the "sand 90\%" sample under the same shear velocity. In the sample "sand 50\%", no PM10 concentration was recorded at the low wind shear velocities as in the other samples. The values in this sample run from $30 \mu \mathrm{g} \mathrm{m}^{-3}$ (background value) to a maximum value of $43,266 \mu \mathrm{g} \mathrm{m}^{-3}$. At shear velocities of 0.31 to $0.39 \mathrm{~m} \mathrm{~s}^{-1}$ the mean concentration increased from 1070 to $5404 \mathrm{\mu g} \mathrm{m}^{-3}$ which is at similar range to the sample of "sand 75\%." The highest mean concentration $\left(29,073 \mu \mathrm{g} \mathrm{m}^{-3}\right)$ was recorded at $0.52 \mathrm{~m} \mathrm{~s}^{-1}$, which is a significantly higher value than the one obtained in the "sand $75 \% . "$

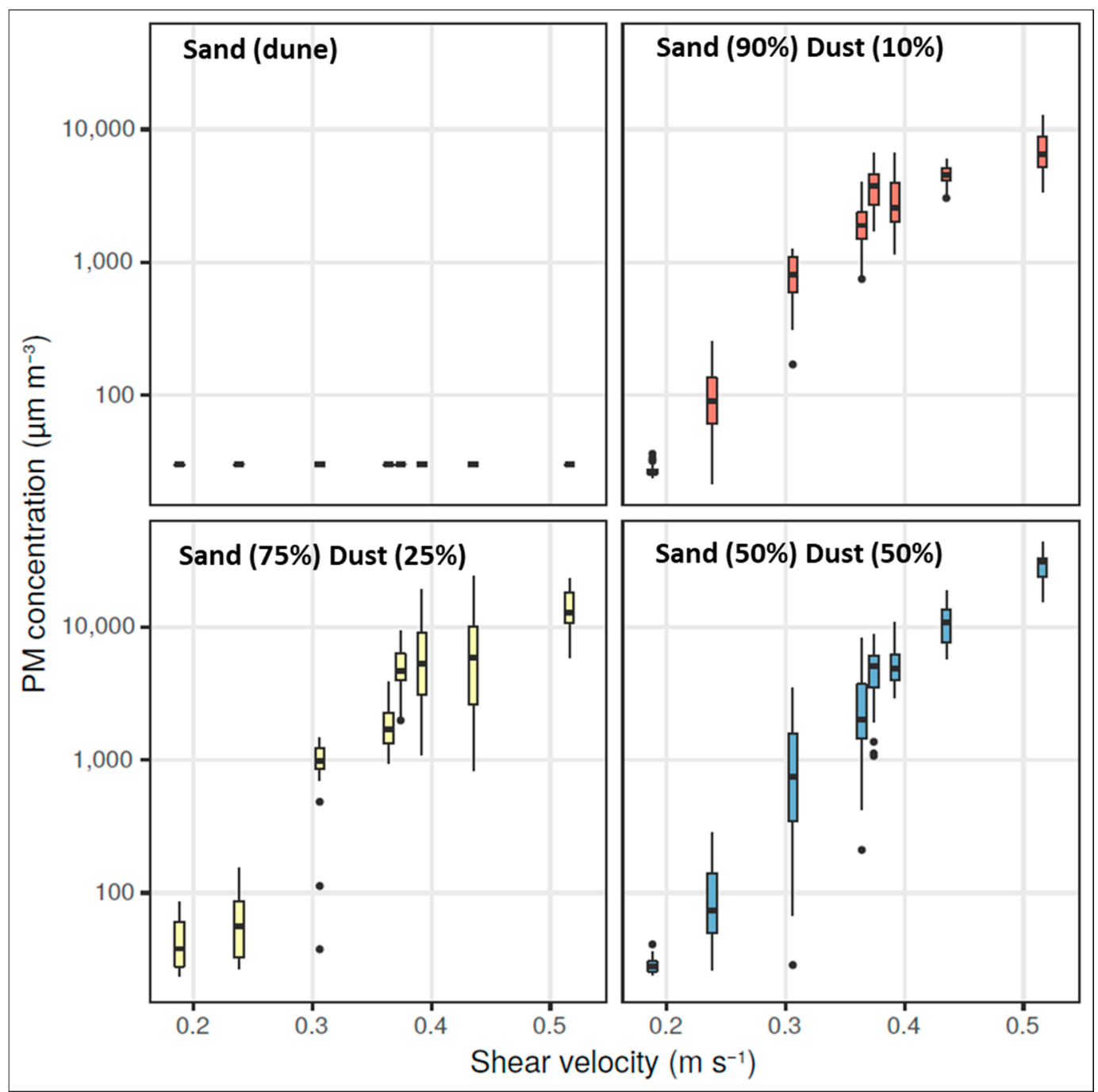

Figure 3. Particulate matter (PM) concentrations measured in the wind tunnel as a result of dust emission from the reference samples under various shear velocities. The reference soils are presented by the weight ratio of clay and silt and sand $10 \%, 25 \%$, and $50 \%$. No dust concentration was recorded for the sand (dune) sample. The average concentration is presented by the solid line inside the minimum-maximum box, and standard deviations are in bar lines. Note that the black dots represent extreme values.

\subsection{Saltation Mass}

The saltation mass measured during the experiment is presented in Figure 4. In most cases of the experiment (total of 120 runs), a vast amount of the material was collected only in the lower traps close to the tunnel bed $(<0.05 \mathrm{~m})$. The saltation threshold at all sand samples is at $\mathrm{u}_{*}=0.31 \mathrm{~m} \mathrm{~s}^{-1}$ as no distinct saltation mass was recorded in the lower shear velocities $\left(0.11-0.24 \mathrm{~m} \mathrm{~s}^{-1}\right)$. The saltation mass in the "sand dune" sample resulted in a range of $0.63 \mathrm{~g}$ (at the saltation threshold) to a maximum value of $8.14 \mathrm{~g}$ at shear velocity of $0.52 \mathrm{~m} \mathrm{~s}^{-1}$ during the a 30 -s run of the experimental procedure. In the 
"sand $90 \%$ " sample, the saltation mass run from $0.48 \mathrm{~g}$ at $0.31 \mathrm{~m} \mathrm{~s}^{-1}$ to a maximum mass of $6.07 \mathrm{~g}$ at shear velocity of $0.52 \mathrm{~m} \mathrm{~s}^{-1}$. These values are significantly lower than the "sand dune" sample at the same shear velocities. Unlike the $100 \%$ sand sample, the dust fraction received in the saltation mass was $4-36 \%$ (Table 1 ). The saltation mass of the "sand $75 \%$ " sample was much lower than the "sand $90 \%$ " sample, and ranged from 0.17 to $4.79 \mathrm{~g}$. From wind shear velocity of 0.31 to $0.43 \mathrm{~m} \mathrm{~s}^{-1}$, the mass increased only $10 \%$, which is at the same level $(7 \%)$ as in the sample of "sand $50 \%$ ". The maximum value of the dust fraction in the "sand 75\%" sample was measured at a wind velocity of $0.39 \mathrm{~m} \mathrm{~s}^{-1}$. The maximum amount of the dust fraction in the saltation (26\%) was measured from wind velocity of 0.39 to $0.52 \mathrm{~m} \mathrm{~s}^{-1}$ (Table 1 ).

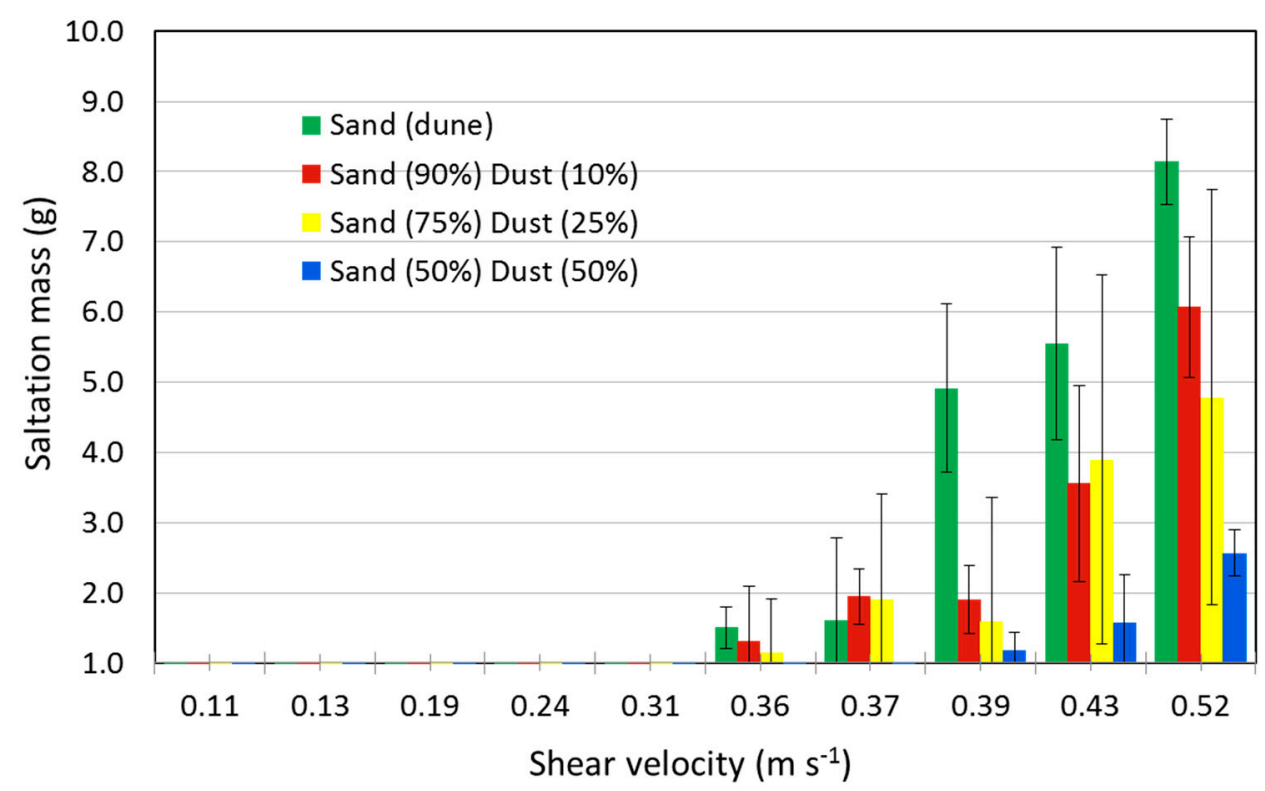

Figure 4. Saltation mass from the wind tunnel measurements of the reference samples under various shear velocities. Note that no distinct saltation mass was recorded in shear velocity below $0.31 \mathrm{~m} \mathrm{~s}^{-1}$.

Table 1. The dust fraction received in the saltation mass calculated as the class weight of the dust particles $(<63 \mu \mathrm{m})$ in the total weight of the saltation: $[1-($ dust $(\mathrm{g}) /$ sand $(\mathrm{g})+$ dust $(\mathrm{g})]$. Note that no saltation was recorded in shear velocity below $0.31 \mathrm{~m} \mathrm{~s}^{-1}$.

\begin{tabular}{ccccc}
\hline Shear Velocity (m s & Sand (Dune) & $\begin{array}{c}\text { Sand (90\%) } \\
\text { Dust (10\%) }\end{array}$ & $\begin{array}{c}\text { Sand (75\%) } \\
\text { Dust (25\%) }\end{array}$ & $\begin{array}{c}\text { Sand (50\%) } \\
\text { Dust (50\%) }\end{array}$ \\
\hline 0.11 & N/A & N/A & N/A & N/A \\
\hline 0.13 & N/A & N/A & N/A & N/A \\
\hline 0.19 & N/A & N/A & N/A & N/A \\
\hline 0.24 & N/A & N/A & N/A & 0.18 \\
\hline 0.31 & 0 & 0.04 & 0.12 & 0.22 \\
\hline 0.36 & 0 & 0.36 & 0.19 & 0.17 \\
\hline 0.37 & 0 & 0.08 & 0.19 & 0.26 \\
\hline 0.39 & 0 & 0.11 & 0.34 & 0.25 \\
\hline 0.43 & 0.01 & 0.11 & 0.15 & 0.26 \\
\hline 0.52 & 0 & 0.11 & 0.18 &
\end{tabular}

The calculated saltation flux refers to the mass of all the particles; sand, silt, and clay, that pass a specific distance over the surface (Section 2.2, Equation (2)). With all soil samples, the saltation flux was started at shear velocity $0.31 \mathrm{~m} \mathrm{~s}^{-1}$ as shown in the record of the saltation mass (Figure 4). 
The calculated PM10 flux refers to transported particles from the surface (Section 2.2, Equation (3)). The results show a linear positive correlation between the saltation flux and the PM10 flux (Figure 5) in all soil samples. As the amount of dust in the sample decreases, both the saltation flux and the PM10 emission decrease. The highest correlation was recorded in the "sand $90 \%$ " $\left(R^{2}=0.99\right)$, while the (relatively) lowest correlation was recorded in the sample of "sand $50 \%$ " $\left(R^{2}=0.91\right)$. Since no dust was recorded in the sand dune sample, a correlation with saltation is not presented.

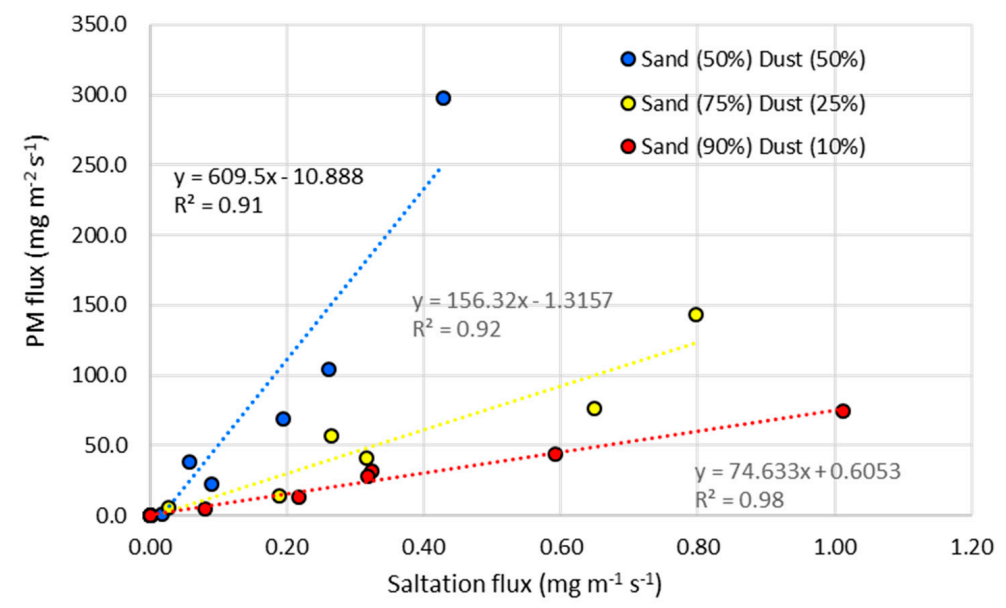

Figure 5. Correlation between saltation flux and PM10 (PM that is less than 10 micrometers in diameter) flux calculated for each soil sample under all the shear velocities applied in the wind tunnel.

\subsection{Sandblasting Efficiency}

Sandblasting efficiency is the dust flux produced by a unit horizontal of saltation flux (Section 2, Equation (3)). The sandblasting efficiency calculated for the various wind shear velocities is presented in Figure 6. In general, as the amount of dust in the sample increases, the sandblasting efficiency increases as well. The highest values of sandblasting were obtained in the sample of "sand $50 \%$ ". The values ranged from $0.25 \mathrm{~m}^{-1}$ at a shear velocity of $0.36 \mathrm{~m} \mathrm{~s}^{-1}$ to $0.7 \mathrm{~m}^{-1}$ at a shear velocity of $0.52 \mathrm{~m} \mathrm{~s}^{-1}$. Since no dust was recorded from the sample of sand dune in this study, the sandblasting efficiency was not calculated.

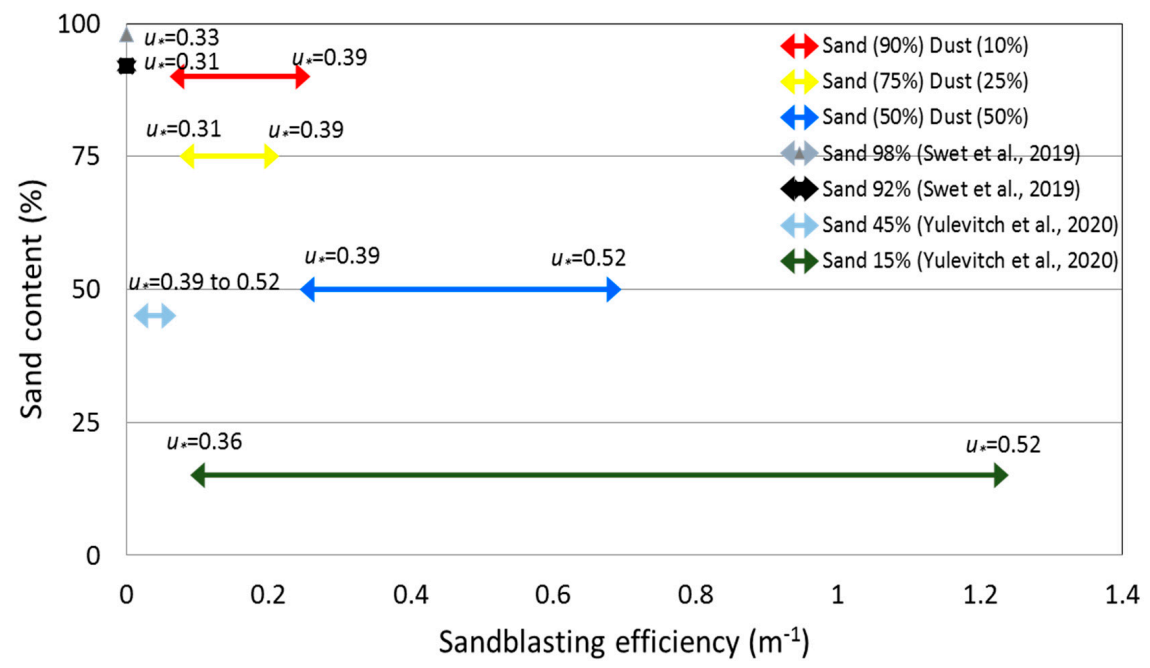

Figure 6. Sandblasting efficiency calculated for soils with different content of sand under a range of wind velocities. In addition, the chart shows the sandblasting efficiency of previously published studies of samples with different sand content $[15,16]$. 


\section{Discussion}

The soil samples tested in this study (Figure 1) represent a range of soil texture in dust sources of sandy and non-sandy soils. The most productive areas for dust are located mainly in arid regions, such as playas (dry lakes) in the Mojave Desert with about 35\% sand content [24]. In the Middle-East and North Africa [25-27], the source areas are characterized by a silt-loam (loess) soil with a clay fraction up to $30 \%$ [28], including loess soils in the northern Negev that are subjected to intensive agricultural activities [12,29]. Major dust sources in the Chinese and the Mongolian deserts are identified with a range of $0.7-11.9 \%$ clay, $1.8-34.1 \%$ silt, and $2.3-53.0 \%$ sand [30]. Unlike common dust sources, sand dunes have a low content of silt and clay ( 2\%). However, recently they were considered to be dust sources $[15,23]$ and as such a sample of sand dune was tested in this study.

The results of the dust PM show an increase concentration as the amount of the clay-silt fraction in the sample is higher (Figure 3). Yulevitch et al. [16] have presented a similar trend with highest PM10 flux for a sample with clay-silt content of $85 \%$. Basically, the increase of PM10 concentration under such conditions is related to the higher availability of dust content in the sample. Since the amount of dust particles in the soil samples "sand 90\%" and "sand 75\%" is relatively low, it can be assumed that the dust emission at velocity $>0.4 \mathrm{~m} \mathrm{~s}^{-1}$ could have been an underestimation for such soils with unlimited dust-particle supply $[10,16]$. In the sample of "sand 50\%;" however, the highest PM10 concentration was recorded in the strongest shear velocity $\left(0.52 \mathrm{~m} \mathrm{~s}^{-1}\right)$, which indicate on sufficient dust content in the sample for continues emission. the distinct dust threshold for all samples is at $0.24 \mathrm{~m} \mathrm{~s}^{-1}$, while in sample "sand 75\%" a PM concentration was recorder already at $0.19 \mathrm{~m} \mathrm{~s}^{-1}$.

As for the "sand dune" sample, no dust concentration was recorded at all shear velocities. Though, recent studies have shown the potential of dust generation from sand. Huang et al. [23] showed that under wind shear velocity of $0.3 \mathrm{~m} \mathrm{~s}^{-1}$ the PM10 fluxes in the Oceano sand is smaller than those fluxes from most non-sandy soils ( 1 and $150 \mu \mathrm{g} \mathrm{m}^{-2} \mathrm{~s}^{-1}$, respectively). Swet et al. [15] recorded PM10 concentration of $0.01 \mathrm{\mu g} \mathrm{m}^{-3}$ from sand dune with $<2 \%$ clay content under wind shear velocity of $0.3 \mathrm{~m} \mathrm{~s}^{-1}$ in the wind tunnel experiment. They concluded that the dominant dust emission mechanism from sand dunes is clay coatings removal, with a relatively small contribution from re-emission of loose-settled dust. In sands containing higher amounts of dust-sized particles, the relative contribution of the re-emission mechanism increases drastically. It is reasonable to assume that in our study there was a dust emission from the "sand" sample by the clay-coating removal. However, our measurement resolution in this study for samples with $<10 \%$ dust content were probably not sensitive enough to distinct PM10 concentration values that are significantly above the background value of the experiment $\left(30 \mu \mathrm{g} \mathrm{m}^{-3}\right)$.

Dust emission is significantly associated with the saltation process. In all the samples of this study, a distinct saltation starts at shear velocity of $0.31 \mathrm{~m} \mathrm{~s}^{-1}$ (Figure 4). A saltation threshold in such velocity was obtained in many studies on sand dunes [8] as well as the trend of increasing sand flux with the shear velocity (Figure 4). The positive linear-correlation between the saltation flux and the PM10 flux was relatively high $\left(R^{2}=0.91-0.99\right)$ in all the non-sandy samples (Figure 5). Strong correlations between saltation and dust flux were found also in previews studies on dust emission from non-sandy soils by wind tunnels [17,31,32]. Nonetheless, Sweeney and Mason [33] show that in a Pleistocene loess deposits (Nebraska, USA) the dust may emit without saltation with a lower threshold $\left(\mathrm{u}_{*}=0.26\right.$ to $0.30 \mathrm{~m} \mathrm{~s}^{-1}$ ) than the saltation threshold $\left(\mathrm{u}_{*}=0.33\right.$ to $\left.0.44 \mathrm{~m} \mathrm{~s}^{-1}\right)$.

To further test the relationships between saltation and dust emission, the sandblasting efficiency was examined with comparison to other works (Figure 6). Basically, the sandblasting efficiency increases with the shear velocity as long as there is available dust particle in the soil for emission. The highest values of sandblasting in this study were obtained in the sample of "sand 50\%", which contains enough amount of dust for emission. When comparing the sandblasting efficiency values with other works conducted in wind tunnel experiment, it revealed that the sandblasting efficiency increases as a function of the amount of dust in the sample and wind velocity. The highest values were recorded at the sample of " $15 \%$ sand" ( $85 \%$ dust), 0.10 to $1.3 \mathrm{~m}^{-1}$, under velocities of 0.39 and $0.52 \mathrm{~m} \mathrm{~s}^{-1}$, 
respectively [16]. The sandblasting efficiency of the "sand 90\%" sample of this study is not presented since no dust was recorded from the sample. However, Swet et al. [15] calculated a sandblasting efficiency of $1.73 \times 10^{-7} \mathrm{~m}^{-1}$ from active sand dune at $0.30 \mathrm{~m} \mathrm{~s}^{-1}$.

Wind tunnels enabled targeted experiments on dust emission processes, in which the empirical data can be used for parametrization of dust models and for validation of model results. Yet, there is little quantitative understanding of how the wide range of particle sizes in realistic dust-emitting soils affects the shear velocity threshold. The dust emission threshold parameterizations used in most models are descriptions of the threshold friction velocity of a dry, bare soil composed of particles of a single grain size. Consequently, dust emissions in models generally increase monotonically with a soil's clay content, and thus do not capture the potentially important mitigating impact of clay particles in raising the threshold friction velocity. Shao and $\mathrm{Lu} \mathrm{[10]} \mathrm{parameterized} \mathrm{the} \mathrm{threshold} \mathrm{as} \mathrm{the} \mathrm{wind}$ velocity at which the aerodynamic torque on a surface particle exceeds that generated by gravity and the interparticle forces with surrounding sand particles. An improved dust emission scheme incorporates saltation bombardment and aggregates disintegration [34]. The statement of the scheme is that dust emission is proportional to streamwise saltation flux, but the proportionality depends on soil texture. A critical problem in dust research is to estimate size-resolved dust emission rates, which requires reliable dust emission estimates for specific size ranges [35]. Thus, wind tunnel experiments can be used to expand the dust formulation by accounting for the entire particle distribution of the soil (and not just the presence of clay), and accounting for the variability of sand (saltation) particle sizes.

This study has some limitations that are discussed as follow. First, we applied four soil samples, which may not represent the entire range of soil texture. However, these samples are common in many soils that are associated with dust emission processes. Second, the use of a wind tunnel to examine the dust emission may not reflect the natural wind in the field where the velocity and direction are constantly changing. However, the controlled wind velocities by the tunnel makes it possible to examine the emission thresholds of various soil samples. Third, the saltation and dust fluxes calculated in this study by the wind tunnel experiment do not necessarily fit the "real" values measured in the field, but it does allow to a quantitative comparison of sandblasting efficiency.

\section{Conclusions}

This study examined empirically the dust emission thresholds in loess soils with different content of sand-sized particles. The significance of this study was to provide empirical information on the link between soil particle size distribution and saltation and dust emission thresholds. The results of the wind tunnel experiment show that dust PM10 emission threshold is strongly associated with the saltation threshold. As such, the direct aerodynamic lifting of loose dust particle was not distinct in this study. Under conditions of dust emission: (i) the dust flux increases as the amount of the clay-silt fraction in the soil is higher, (ii) there is a logarithmic increase of dust flux with the of the shear velocity, (iii) the rate of the dust flux under certain saltation is subjected to the available dust amount in the soil during a wind event, and (iv) in soil with non-limited dust supply in the soil, the maximum rate of the dust flux is limited to the capacity of the saltation flux under certain shear velocity. The results of the sandblasting efficiency highlight the significance of the soil disturbance and aggregate disintegration in increasing dust emission from loess soils. The combination of loose sand particles in soils containing distinct amount of dust particles ( $>10 \%)$ is favor for dust emission. The findings of this study can be processed into parametrization in dust emission models. They can also support management strategy of soils in preventing dust emission by keeping the soil aggregation.

Author Contributions: Conceptualization, I.K.; methodology, I.K. and A.R.; formal analysis, A.R.; writing—original draft preparation, A.R.; writing — review and editing, A.R., M.B.-H. and I.K.; funding acquisition, I.K. All authors have read and agreed to the published version of the manuscript.

Funding: This research received no external funding.

Conflicts of Interest: The authors declare no conflict of interest. 


\section{References}

1. Kok, J.F.; Ridley, D.A.; Zhou, Q.; Miller, R.; Zhao, C.; Heald, C.L.; Ward, D.S.; Albani, S.; Haustein, K. Smaller desert dust cooling effect estimated from analysis of dust size and abundance. Nat. Geosci. 2017, 10, $274-278$. [CrossRef] [PubMed]

2. Katra, I.; Gross, A.; Swet, N.; Tanner, S.; Krasnov, H.; Angert, A. Substantial dust loss of bioavailable phosphorus from agricultural soils. Sci. Rep. 2016, 6, 24736. [CrossRef] [PubMed]

3. Yitshak-Sade, M.; Novack, V.; Katra, I.; Gorodischer, R.; Tal, A.; Novack, L. Non-anthropogenic dust exposure and asthma medication purchase in children. Eur. Respir. J. 2014, 45, 652-660. [CrossRef] [PubMed]

4. Krasnov, H.; Katra, I.; Novack, V.; Vodonos, A.; Friger, M.D. Increased indoor PM concentrations controlled by atmospheric dust events and urban factors. Build. Environ. 2015, 87, 169-176. [CrossRef]

5. Klose, M.; Shao, Y.; Li, X.; Zhang, H.; Ishizuka, M.; Mikami, M.; Leys, J. Further development of a parameterization for convective turbulent dust emission and evaluation based on field observations. J. Geophys. Res. Atmos. 2014, 119, 10441-10457. [CrossRef]

6. Kok, J.F.; Mahowald, N.; Fratini, G.; Gillies, J.A.; Ishizuka, M.; Leys, J.F.; Mikami, M.; Park, M.-S.; Park, S.-U.; Van Pelt, R.S.; et al. An improved dust emission model-Part 1: Model description and comparison against measurements. Atmos. Chem. Phys. Discuss. 2014, 14, 13023-13041. [CrossRef]

7. Shao, Y.; Raupach, M.R.; Findlater, P.A. Effect of saltation bombardment on the entrainment of dust by wind. J. Geophys. Res. Space Phys. 1993, 98, 12719. [CrossRef]

8. Kok, J.F.; Parteli, E.J.; Michaels, T.i.; Karam, D.B. The physics of wind-blown sand and dust. Rep. Prog. Phys. 2012, 75, 106901. [CrossRef]

9. Bagnold, R.A. The Physics of Blown Sand and Desert Dunes; Methuen and Company Limited: London, UK, 1941.

10. Shao, Y.; Lü, H. A simple expression for wind erosion threshold friction velocity. J. Geophys. Res. Space Phys. 2000, 105, 22437-22443. [CrossRef]

11. Swet, N.; Katra, I. Reduction in soil aggregation in response to dust emission processes. Geomorphology 2016, 268, 177-183. [CrossRef]

12. Katra, I. Soil Erosion by Wind and Dust Emission in Semi-Arid Soils Due to Agricultural Activities. Agronomy 2020, 10, 89. [CrossRef]

13. Ben-Hur, M.; Agassi, M. Predicting interrill erodibility factor from measured infiltration rate. Water Resour. Res. 1997, 33, 2409-2415. [CrossRef]

14. Roskin, J.; Katra, I.; Blumberg, D.G. Particle-size fractionation of eolian sand along the Sinai-Negev erg of Egypt and Israel. GSA Bull. 2013, 126, 47-65. [CrossRef]

15. Swet, N.; Elperin, T.; Kok, J.F.; Martin, R.L.; Yizhaq, H.; Katra, I. Can active sands generate dust particles by wind-induced processes? Earth Planet. Sci. Lett. 2019, 506, 371-380. [CrossRef]

16. Yulevitch, G.; Danon, M.; Krasovitov, B.; Fominykh, A.; Swet, N.; Tsesarsky, M.; Katra, I. Evaluation of wind-induced dust-PM emission from unpaved roads varying in silt content by experimental results. Atmos. Pollut. Res. 2020, 11, 261-268. [CrossRef]

17. Tanner, S.; Katra, I.; Haim, A.; Zaady, E. Short-term soil loss by eolian erosion in response to different rain-fed agricultural practices. Soil Tillage Res. 2016, 155, 149-156. [CrossRef]

18. Katra, I. Comparison of Diverse Dust Control Products in Wind-Induced Dust Emission from Unpaved Roads. Appl. Sci. 2019, 9, 5204. [CrossRef]

19. Sharratt, B.; Wendling, L.; Feng, G. Windblown dust affected by tillage intensity during summer fallow. Aeolian Res. 2010, 2, 129-134. [CrossRef]

20. Singh, P.; Sharratt, B.; Schillinger, W.F. Wind erosion and PM10 emission affected by tillage systems in the world's driest rainfed wheat region. Soil Tillage Res. 2012, 124, 219-225. [CrossRef]

21. Van Pelt, R.S.; Baddock, M.; Zobeck, T.M.; Schlegel, A.J.; Vigil, M.F.; Acosta-Martinez, V. Field wind tunnel testing of two silt loam soils on the North American Central High Plains. Aeolian Res. 2013, 10, 53-59. [CrossRef]

22. Asensio, C.; Lozano, F.J.; Gallardo, P.; Giménez-Fernández, A. Soil wind erosion in ecological olive trees in the Tabernas desert (Southeastern Spain): A wind tunnel experiment. Solid Earth 2016, 7, 1233-1242. [CrossRef]

23. Huang, Y.; Kok, J.F.; Martin, R.L.; Swet, N.; Katra, I.; Gill, T.E.; Reynolds, R.L.; Freire, L.S. Fine dust emissions from active sands at coastal Oceano Dunes, California. Atmos. Chem. Phys. Discuss. 2019, 19, 2947-2964. [CrossRef]

24. Katra, I.; Lancaster, N. Surface-sediment dynamics in a dust source from spaceborne multispectral thermal infrared data. Remote Sens. Environ. 2008, 112, 3212-3221. [CrossRef] 
25. Ginoux, P.; Prospero, J.M.; Gill, T.E.; Hsu, N.C.; Zhao, M. Global-scale attribution of anthropogenic and natural dust sources and their emission rates based on MODIS Deep Blue aerosol products. Rev. Geophys. 2012, 50. [CrossRef]

26. Prospero, J.M.; Nicholson, S.E.; Ginoux, P.; Torres, O.; Gill, T.E. Environmental characterization of global sources of atmospheric soil dust identified with the NIMBUS 7 Total Ozone Mapping Spectrometer (TOMS) absorbing aerosol product. Rev. Geophys. 2002, 40. [CrossRef]

27. Washington, R.; Todd, M.; Middleton, N.J.; Goudie, A. Dust-Storm Source Areas Determined by the Total Ozone Monitoring Spectrometer and Surface Observations. Ann. Assoc. Am. Geogr. 2003, 93, 297-313. [CrossRef]

28. Gherboudj, I.; Beegum, S.N.; Marticorena, B.; Ghedira, H. Dust emission parameterization scheme over the MENA region: Sensitivity analysis to soil moisture and soil texture. J. Geophys. Res. Atmos. 2015, 120, 10915-10938. [CrossRef]

29. Shalom, O.; Crouvi, O.; Enzel, Y.; Rosenfeld, D. Locally recycled late Pleistocene loess feeds modern dust storms at the desert margins of the eastern Mediterranean, Israel. Aeolian Res. 2020, 46, 100612. [CrossRef]

30. Laurent, B.; Marticorena, B.; Bergametti, G.; Mei, F. Modeling mineral dust emissions from Chinese and Mongolian deserts. Glob. Planet. Chang. 2006, 52, 121-141. [CrossRef]

31. Houser, C.A.; Nickling, W.G. The emission and vertical flux of particulate matter. Sedimentology 2001, 48, $255-267$.

32. Gelbart, G.; Katra, I. Dependence of the dust emission on the aggregate sizes in loess soils. Appl. Sci. 2020, 10, 5410. [CrossRef]

33. Sweeney, M.; Mason, J.A. Mechanisms of dust emission from Pleistocene loess deposits, Nebraska, USA. J. Geophys. Res. Earth Surf. 2013, 118, 1460-1471. [CrossRef]

34. Shao, Y. Simplification of a dust emission scheme and comparison with data. J. Geophys. Res. Space Phys. 2004, 109. [CrossRef]

35. Shao, Y.; Ishizuka, M.; Mikami, M.; Leys, J.F. Parameterization of size-resolved dust emission and validation with measurements. J. Geophys. Res. Space Phys. 2011, 116. [CrossRef]

(C) 2020 by the authors. Licensee MDPI, Basel, Switzerland. This article is an open access article distributed under the terms and conditions of the Creative Commons Attribution (CC BY) license (http://creativecommons.org/licenses/by/4.0/). 